\title{
Exploring the meaning of arguing in folk culture and language in Ukraine
}

\author{
Iryna Khomenko \\ Doctor of Philosophical Sciences, Professor, Taras Shevchenko National University of Kyiv \\ (Kyiv, Ukraine) \\ E-mail: khomenkoi.ukr1@gmail.com \\ https://orcid.org/0000-0003-3522-2271
}

Khomenko, Iryna (2020) Exploring the meaning of arguing in folk culture and language in Ukraine. Future Human Image, Volume 13, 2020: 24-31. https://doi.org/10.29202/fhi/13/3

This paper aims to explore the meanings of the English word "arguing" in folk culture and language in Ukraine. It first considers the various definitions and concepts concerning Ukrainian arguingrelated words and expressions that can fully or partially represent all the meanings of the English word "arguing." Next, it is studied within the Ukrainian folk tradition proverbs and tales of debates involving the explanation of the most fundamental orientations and patterns, which could constitute the understanding of arguing and public debating there.

Keywords: arguing, Ukrainian culture, Ukrainian language, interpersonal communication, public debating

Received: February 10, 2020; accepted: March 1, 2020

\section{Introduction}

Many cross-cultural research projects exploring arguing have been conducted lately. "Arguing is a fundamental human activity, perhaps the primary means of coming to new understandings" (Hample, 2005: 16). People often argue over controversial issues. They use arguments for daily decision-making processes in their ordinary life. Arguing reflects cultural beliefs, traditions, patterns about self-identity, relationships in interpersonal communication. The papers on the cultural influences on arguing are of particular interest (Hample, 2018; Oetzel et al., 2001; Ting-Toomey, 2010). Scholars are interested in answering questions about how people with different cultural traditions relate to interpersonal communication, particularly to various kinds of arguing. The general project of comparing argumentation in various countries across the globe should be mentioned here (Hample, 2018; Hample \& Anagondahalli, 2015; Hample \& Rapanta, 2015; Lewiński et al., 2018; Kim et al., 2018; Dufour \& Hample, 2018; Demir \& Hample, 2019; Khomenko \& Hample, 2019). In this regard, it is interesting to examine

(C) Khomenko, Iryna, 2020 
folk cultural predispositions and understandings of interpersonal arguing as a background of modern views.

This paper is one of the first attempts to explore the meaning of arguing in folk culture and language in Ukraine. The author tried to sift through of Ukrainian folk tales and proverbs and figure out the main fundamental orientations and patterns of behavior in various situations of interpersonal arguing. Also, the paper has been presented the results of searching Ukrainian words and expressions made in defining the similar concepts and meanings as the English word arguing.

\section{Ukrainian arguing-related words and expressions}

The concept and meaning of the English word arguing have rarely been cross-examined with Ukrainian culture and Ukrainian language. Unfortunately, there are no studies that examine whether there is such a concept or such a Ukrainian word or expression that corresponds exactly to the meaning of the English word "arguing." In this regard, we experienced some challenges in translating this English word into Ukrainian.

To explore its meaning in Ukrainian, we paid particular attention to the key terms of argumentation theory concerning arguing, namely "argue", "argument", "debate", "discussion", "conflict", "disagreement", and others. These terms often do not have a precise, unambiguous meaning in English. That brought much complexity in finding their Ukrainian equivalents. Also, some of these terms are not commonly used in everyday Ukrainian. They usually occur only in scientific discourse.

Begin with the term "argumentation" (argumentative/Ukr). It rarely can be met in ordinary communication of Ukrainians. Other terms are more often used, namely "justification" (obgruntuvannia/Ukr), "proof” or "evidence" (dovedennia/Ukr), and reasoning (mirkuvannia/ $\mathrm{Ukr}$ ). In this sense, argumentation is not a form of interaction, in which arguers resolve a conflict of opinions using real arguments. Ukrainians often encounter the definition of argumentation as reasoning, aimed at justification (proof, evidence) of an arguer's point of view. It is interesting that the Ukrainian word "mira" (measure) forms the basis of the term "mirkuvannia" (reasoning). "Mira" is to discover the exact size or amount of something. It can be assumed that the meaning of the term "mirkuvannia" among other things, contains a measure of evaluation too. In other words, the meaning of the Ukrainian word "mirkuvannia" includes not only explicitly the process of thinking about something but also implicitly its evaluation.

Second, let's consider the term "argument." There is some genuine ambiguity about what argument means in English. It can mean (A) proof or demonstration, (B) exchange of reasons, and (C) verbal fight.

(A) Proof or demonstration

Among modern logicians who study argument from a formal approach, an argument is defined as a set of statements among which one of them could follow from the others. Here words "argument," "reasoning," and "inference" are synonyms. Ukrainian words "mirkuvannia," "vyvid," "vysnovuvannia" are considered to be the most relevant translation in this case.

(B) Exchange of reasons

Many contemporary scholars try to reconceptualize argument in some other way to better characterize its key features in real communication. In this regard, the argument is considered 
as a set of statements that seeks to justify a conclusion by supporting it with premises; to defend it from objections; or both goals. For example, Hample consider argument as "a conclusion supported by a reason," and its function is to "create meaning" (Hample, 2005: 19).

Scholars usually use the traditional approach here: the structure of the argument consists of premises and a conclusion. The conclusion is a statement that is based on other accounts, called premises. Both notions are mutually interdependent and hang upon the context of argumentation. We can find the same terms in Ukrainian: "zasnovky" (premises) and "vysnovok" (conclusion). Many contemporary scholars try to reconceptualize argument in some other way to better characterize its practical features.

However, it should be stressed that informal logicians focus solely on such kind of reasoning as a real argument. Unfortunately, in spite of numerous papers, books, and textbooks published over the last thirty years, consensus as to what a real argument is not been achieved so far. We can only point out the fact that the informal logicians unify around the idea that a real argument is a kind of reasoning, which is not the subject matter of formal logic.

About clarifying this term, it could be considered as a complex kind of argument, which is used in argumentation as a form of dialogical interaction, where arguers aim is to resolve a conflict of opinions expressed by verbal means.

We can highlight the key features of such arguments (Khomenko \& Shramko, 2019; Khomenko, 2018):

1. Unlike formal logic, which uses artificial language, the real argument is expressed by natural language.

2. The real argument is dialogical. Here arguing requires at least two arguers. They express to each other divergent points of view on a certain question and, at the same time, should keep in mind objections, which they may have.

3. The real argument relates to everyday communication. In this regard, the artificial reasoning from textbooks on logic is not relevant to real arguments.

4. The real argument is mostly a permissible one. We can see that some arguments, which we take to be good, are not sound by reflecting on examples of perfectly acceptable arguments whose premises are not all true, or whose inferential step is not deductively valid.

5. One of the key features of the real argument is its incompleteness. Arguers often do not use all premises and conclusions in such arguments. Some of them do it to confuse the opponents, but sometimes this case occurs when arguers do not have sufficient skills to express their thoughts clearly.

6. The real argument is dependent on the context of utterance.

Proponent and opponent use real arguments in face-to-face arguing. However, the translation of the expression 'real argument' from English into Ukrainian is a great issue. In order to provide an adequate translation, we used the Ukrainian phrase "argumentatyvne mirkuvannia" (Khomenko, 2019). It is not used in ordinary communication; it is a scientific term.

Also, it should be stressed that Ukrainians often understand the term "argument" as a "premise" or "reason" (argument/Ukr). Sometimes it can be translated from English to Ukrainian as "rezon."

(C) Verbal fight

Within this meaning, we consider the words "argument" and "arguing" as synonyms. The Ukrainian translation is "superechka." This word has positive and negative connotations in 
Ukrainian. Here it should be stressed that the negative understanding is slightly more prevalent among Ukrainians. They interpret arguing in a face-to-face situation as speaking angrily to someone, having a heated discussion with somebody. The person not telling somebody that he disagrees with something. He or she expresses his anger in a loud voice. In this sense, the terms "arguing" (superechka/ Ukr) and "quarrel" (svarka/Ukr) can be used as synonymous. For example, such expression as "bazarna svarka" is an idiom in Ukrainian. This means the marketplace quarrel.

In this context, Ukrainians prefer to use soft power. They usually use instead of "argument" and "arguing" such terms as a "conversation" (besida, rozmova/Ukr), "discussion" (dyskusiia/ Ukr), "debate" (debaty/Ukr), and "dispute" (dysput/Ukr). For example, these expressions are widely used in Ukraine: politychni debate /Ukr (political debate), and naukova dyskussia/Ukr (scientific discussion).

Also, the term "face-to-face" can be translated as the Ukrainian idiom "vich-na-vich" (eyes-to eyes). The expression "face-to-face arguing" is not used in Ukrainian. Usually, "vichna-vich" is applied for any interpersonal communication when a person meets somebody.

Another interesting fact is if you would like to translate "arguing" into Ukrainian, you should choose between two words - "superechka" or "spor." The first can be used for "faceto-face arguing," and the second usually describes the legal sense of this term.

In general, Ukrainians try to avoid expressions with negative, aggressive connotation in face-to-face arguing. They prefer friendly vocabulary aimed at cooperation and mutual understanding and not at the verbal fight. This can be explained by the peaceful and openminded character of Ukrainian people.

\section{Arguing-related folk wisdom in Ukrainian culture}

In Ukrainian folk culture, Ukrainian society has always been considered as a group where conflict avoidance is viewed more positively than confrontation and face-to-face arguing.

In Ukraine, the concept of arguing overlaps in many cases with conflict and aggression. There is no clear-cut distinction between face-to-face arguing and conflict for most of the Ukrainian people. In this regard, they can be used as synonymous in most cases, and often are both associated with negative meanings. Appeal to Ukrainian folk culture, especially to the Ukrainian fairy tales and proverbs, can help us better understand Ukrainian people's predispositions and beliefs towards face-to-face arguing and its link to conflict ${ }^{1}$.

\section{Face-to-face arguing in Ukrainian folk tales}

Folk fairy tales are a popular genre of Ukrainian traditional folk art. As for the main types of fairy tales in Ukraine, there are two of them: magic fairy tales and stories related to social problems. Face-to-face arguing was typically a subject matter of tales where the key characters were animals. Animal fairy tales tell stories about domestic and wild animals, birds, and even insects. These tales have expressive social undertones. The images of animals serve as an allegory for people with their typical behavior in real life. In Ukrainian folk fairy tales, animals go to war, choose their leaders, love, and argue - just like ordinary humans.

${ }^{1}$ When considering this topic, the author based on various resources. Among them are Digital Library "The Culture of Ukraine" (Digital, 2020; Electronic, 2020). 
In general, such stories explain the common rules of conduct applicable to all situations from real life, particularly to interpersonal communication. The list of famous Ukrainian folk fairy tales about arguing include "Rukavychka" ("Mittens"), "Dva kozlyky" ("Two goats"), "Lysychka-suddia" ("Fox as a judge"), "Dva vovky ta lysytsia" ("Two wolfs and fox"), "Korova, kin ta pes" ("Cow, horse, and dog"), "Zhadibni vedmezhata" (Greedy bear cubs), "Kit i pes" ("Cat and dog") and other stories about animals. Its key features are the following.

(A) Arguer's losing strategy in face-to-face arguing. In the Ukrainian social tales, the subject matters of arguing may be different. Kittens discuss how to split a piece of cheese equally, goats decide who should step aside crossing the bridge, cow, horse, and dog argue who the master's favorite animal, etc. is. The key aim of these tales is to fully convince readers that the friendly communication strategy is better than any face-to-face arguing. According to Ukrainian tales, every arguing leads to conflicts in which both sides lose.

(B) Arguer's inability to solve the problem by face-to-face arguing. In the tales arguers usually cannot solve the problem themselves. They invite a judge/referee to decide the controversial issue. In most cases, judge/referee thinks only about own benefit. It is interesting that a cunning fox typically acts as a referee in the Ukrainian fairy tale. The referee's aim often is to increase the arguer's aggressiveness, to trick both sides. As a result, a judge takes all. For example, in the story, called Fox as a judge, two kittens want to divide the piece of cheese equally. Finally, the fox has eaten all the pieces.

(C) Full rejection of face-to-face arguing as a way to discuss and solve some problems. In most Ukrainian fairy stories, face-to-face arguing is considered a negative way to justify their own position, to critique the view of the opponent, and to solve some problems. The main message of the folk tales is to illustrate that any arguing leads to conflict and misunderstandings. It would be better if such communication were not used in real life.

(D) Differences between men and women in their arguing motivations, understandings, and reactions.

In the Ukrainian tales, we can see the features of the typical roles of man and woman in interpersonal communication. One of them is that men are more aggressive than women in face-to-face arguing. Take the example of the tale about two goats. There are two versions of this story: male and female. In the first case, two male goats tried to cross the narrow bridge. However, neither of them wanted to step aside for the other's benefit. There was arguing, which quickly turned into a scuffle. As a result, they both fell into the river. In the second version, the main characters are two female goats. Their behavior differs considerably. They did not come into conflict. Instead, the goats helped each other: one of them lay down on the bridge, and the other goat stepped over her.

\section{Arguing-related Ukrainian proverbs}

Ukrainian people have always been well-known for their hard-working nature. Good work has always been highly valued in Ukrainian society. This fact is expressed in many Ukrainian proverbs. A lot of dictums highlight the great importance of work in the ordinary life of Ukrainians and harshly condemn time wasted by talking, including face-to-face arguing. For example: "Ne tak shvydko robytsia, jak movytsia" ("Easier said than done"); "Kho bahato hovoryt, toi malo tvoryt" ("The person who talks a lot usually work a little"); "Bilshe dila, menshe sliv" ("More work, than words") and others.

In this regard, face-to-face arguing is considered in the Ukrainian proverbs in a negative context. It is complicated to translate to English the key Ukrainian dictum concerning arguing. 
It is the following: "Nekhai bude hrechka, aby ne superechka" ("Let there be buckwheat, but not an arguing"). It means a complete rejection of the dispute in ordinary life. For Ukrainians, it is better to eat porridge than to argue.

In morals, Ukrainian people give a lot of reasons why they believe that they should not solve problems by arguing. Among them are the following.

(A) Each person has their own view of the problem. The relevant Ukrainian proverbs that illustrate this point are the following. "Skilky holiv, stilky umiv" ("How many heads, so many minds"); Shcho inshe siltse, to inshe slivtse" ("There is a new village, there is a new word"), "Shcho insha khatka, to insha hadka" ("There is a new home, there is a new opinion").

(B) It is better to try to keep silent than arguing. Suitable proverbs are the following: "Menshe hovory, bilshe vchuesh" ("Speak little, hear much"); Slovo - ne horobets, vypustesh - ne spiimaesh" ("A word is not a sparrow. If you get it out, you cannot catch it"); Slukhai sto raziv, a hovory odyn raz (Keep your mouth shut and your ears open). However, you do not find rigid tips in the Ukrainian proverbs. For example, there is not the equivalent of the English dictum: He that is a blab is a scab.

(C) The persons who take part in face-to-face arguing usually are the losers, while the winner is the third side. Let's give some examples: "Dva svariatsia - tertii korystuetsia" ("Two argue, the third profits from this arguing"); "Hlechyk popolam - ni tobi, ni nam" ("Split a jug in half, nobody gets anything").

(D) If you are obliged to argue, you should not be aggressive. Such proverbs are the Illustration for this point. "Krykom duba ne zrubaesh" (You can't cut an oak tree with a scream), "Krykom vohnu ne zhasysh" (Scream cannot put out the fire).

Interestingly, some Ukrainian proverbs overlap with English ones. For example: "Podumai dvichi, a todi skazhy slovo" ("Hear twice before you speak once"); "Na pravdu sliv bahato ne treba" ("Few words are best"); Slovo ne strila, a hlybshe ranyt ("Words cut more than swords"); Umii skazaty, umiq I zamovchaty ("There is time to speak and a time to be silent"), and others.

To sum up, we can conclude that Ukrainian folk wisdom, expressed by numerous fairy tales and proverbs, propose to Ukrainians some tips and recommendations on how they should communicate with each other. As for face-to-face arguing there, the main strategy is to avoid it. It would be better to take no sides with anybody about anything. So, in most of the Ukrainian stories and proverbs, arguing is considered as an aggressive conflict with terrible consequences. According to folk wisdom, interpersonal communication should be based on peaceful cooperation. A shining example of this principle is one of the known Ukrainian tales, called Rukavychka (Mitten).

In this story, one day, the old man lost his mitten in the forest. A mouse ran along. She entered the mitt and sat there. Then a frog jumped by and asked to let her into the mitten. A hare ran along, and he wanted to live in mitten too. After him, a fox, a wolf, a bear, and even a wild boar ran by and wished to move into the mitten-house. Every time the animals argued whether to let in the next tenant and without any aggressive quarrel invited him to come in. They were all seated there. Although the older man went past and the animals scattered, this tale sets an example of how a person should act in a controversial situation.

The Ukrainian proverbs say things about cooperation in the same cases too: "Odyn rozum dobre, a dva krashche" (One mind is good, but two minds are better); "Druzhba ta braterstvo naikrashchi bahatstva" ("Friendship and brotherhood are the best wealth"). However, at the same time, Ukrainians do not forget that "Kozhna holova maie svii rozum" ("Each head has own mind"). 


\section{Conclusions}

This paper focuses on arguing in the Ukrainian cultural context. It is important because "arguing, which refers to exchanging reasons, not necessarily to an emotional explosion, is a fundamental human activity" (Hample 2005). The paper is based on the view that arguing reflects cultural beliefs about self-identity and relationships. In this regard, the study of the cultural experience and cultural influences concerning arguing in Ukrainian folk tradition and language is particularly interesting.

We began with the analysis of arguing-related words in the Ukrainian language and compared their meanings with the meanings of English words and expressions. To sum up, it can be noted that the Ukrainian language has its own argument-related words and expressions. However, it is not always Ukrainian words that fully correspond to the meanings of English ones.

Next, it was investigated by several Ukrainian folk fairy tales and proverbs. It was concluded that Ukrainian folk wisdom could be characterized as non-argumentative and arguing-avoidant. As I showed, traditionally in tales and proverbs, the key pattern of behavior concerning arguing was the following - a person should be aside of controversies. Otherwise, when a person was involved in a conflict arguing should be considered as a peaceful and constructive discussion. It could be suggested that in Ukrainian folk wisdom, the best way of arguing was to lead by the stance that finding a compromise or common solution. Thus, in tales and proverbs, Ukrainian society was identified as a society that prefers non-argumentative, non-confrontational, and conflict avoidance strategy of arguing over direct argumentation and confrontation.

\section{[ㅁ] References}

Digital library "The Culture of Ukraine" (2010) National Parliamentary Library of Ukraine. https://elib.nlu.org.ua/

Demir, Yeliz, and Dale Hample (2019) A Cross-Cultural Study of Argument Orientations of Turkish and American College Students: Is Silence Really Golden and Speech Silver for Turkish Students? Argumentation, 33(4), 521-540.

Dufour, M. and Dale Hample (2018) French interpersonal argument: fundamental understandings. Argumentation and inference: Proceedings of the 2nd European Conference on Argumentation, Fribourg 2017, vol. 1, ed. S. Oswald and D. Maillat, London: College Publications, 51-74.

Electronic Archive of Ukrainian Folklore (2020) Laboratory of Folklore Research. https:// folklore-archive.org.ua

Hample, Dale (2005) Arguing: Exchanging reasons face to face. New Jersey, NJ: Lawrence Erlbaum Associates.

Hample, Dale (2018) Interpersonal arguing, New York: Peter Lang. https://doi.org/10.3726/ b12877

Hample, Dale, and Deepa Anagondahalli (2015) Understandings of arguing in India and the United States: Argument frames, personalization of conflict, argumentativeness, and verbal aggressiveness. Journal of Intercultural Communication Research, 44 (1), 1-26. https://doi.org/10.1080/17475759.2014.1000939 
Hample, Dale, and Chrysi Rapanta (2015) Orientations to interpersonal arguing in the United Arab Emirates, with comparisons to the United States, China, and India. Journal of Intercultural Communication Research, 44 (4), 263-287. https://doi.org/10.1080/1747 5759.2015.1081392

Lewiński, Marcin, Dale Hample, João Sàágua, and Dima Mohammed (2018) Arguing in Portugal: A cross-cultural analysis. Journal of International and Intercultural Communication, Vol.11, Issue 3, 233-253. https://doi.org/10.1080/17513057.2018.14 50888

Kim, Youllee, Sungeun Chung, and Dale Hample (2018) How do culture, individual traits, and context influence interpersonal arguing? A comparative study of South Korea and the United States. Paper presented at the annual meeting of the National Communication Association, Salt Lake City, UT. https://doi.org/10.1007/s10503-019-09482-2

Khomenko, Iryna (2018) A Look at Informal Logic. Future Human Image, 9, 52-62. https:// doi.org/10.29202/fhi/9/5

Khomenko, Iryna, and Dale Hample (2019) Comparative analysis of Arguing in Ukraine and the USA. Proceedings of the Ninth Conference of the International Society for the Study of Argumentation. Amsterdam: Sic Sat, 628-639.

Khomenko, Iryna, and Yaroslav Shramko (2019) Is logic a normative science, and how could it be normative? Philosophical Thought, 6, 52-63. https://doi.org/10.15407/fd2019.05.052

Oetzel, John, Stella Ting-Toomey, Tomoko Masumoto, Yumiko Yokochi, Xiahui Pan, Jiro Takai, and Richard Wilcox (2001) Face and facework in conflict: A cross-cultural comparison of China, Germany, Japan, and the United States. Communication Monographs, Vol. 68(3), 235-258. https://doi.org/10.1080/03637 750128061

Ting-Toomey, Stella (2010) Applying dimensional values in understanding intercultural communication. Communication Monographs, Vol. 72(2), 169-180. https://doi. org/10.1080/03637 751003790428 . 